\title{
Audit
}

\section{A clinical audit on pap smears reported in a tertiary care centre in Sri Lanka}

\author{
L.D.S. De Silva ${ }^{1}$, R. Gunawardene ${ }^{1}$, E.H. Siriweera ${ }^{1}$, R. Waduge ${ }^{1}$, P.M.R. Deniyegedara ${ }^{2}$, \\ S. Wijetunge ${ }^{1}$ \\ ${ }^{1}$ Department of Pathology, Faculty of Medicine, University of Peradeniya, Sri Lanka. \\ ${ }^{2}$ Department of Pathology, Teaching Hospital, Peradeniya, Sri Lanka.
}

Submitted on 24.05.2021. Accepted for publication on 27.07.2021.

\section{Introduction}

Cervical cancer is the most common gynecological cancer worldwide, with developing countries bearing a disproportionately high disease burden (1). This is the second most common cancer among Sri Lankan women. According to the World Health Organization (WHO) there were 604,127 new cases of cervical carcinoma diagnosed worldwide in the year 2020, while 341,831 deaths were reported following the diagnosis of cervical cancer (2). Studies have shown that early detection and treatment can reduce morbidity and mortality by more than $70 \%$ (3).

Almost all cases of cervical malignancies (>99\%) occur following a high-risk human papillomavirus (HPV) infection. Therefore, early identification of high-risk HPV infection and the related premalignant histological changes plays a vital role in reducing the incidence of cervical cancer.

Corresponding author: Dr Sulochana Wijetunge Senior Lecturer and Consultant Pathologist Department of Pathology, Faculty of Medicine University of Peradeniya, Sri Lanka sulochana.wijetunge@med.pdn.ac.lk
The pap test/pap smear is widely used as a screening tool to detect premalignant cervical lesions, HPV cytopathic effects, and for the early detection of cervical malignancies, since it is a cost-effective, reliable, and simple method. In developed countries, the pap test is used in combination with high-risk HPV DNA testing when required. However, in most developing countries, in the absence of freely available HPV DNA assay facilities, the pap test remains the most important screening tool(4).

Cytological diagnoses in pap smears are reported universally according to the Bethesda Criteria (5). For quality control purposes, it is important that each institution performs audits on pap smear reporting outcomes to assess if their reporting rates are compatible with globally accepted benchmarks(5).

The objective of this audit was to determine diagnostic rates for main Bethesda diagnostic categories and to determine the incidence of epithelial cell abnormalities in pap smears examined at Teaching Hospital, Peradeniya (THP) from 2017 to 2019.

This is an open access article licensed under a Creative Commons Attribution-ShareAlike 4.0 International License. (CC BY-SA 4.0), which permits unrestricted use, distribution and reproduction in any medium, provided the original author and source are attributed and materials are shared under the same license. 


\section{Methods}

This audit was carried out on pap smears received from gynecology clinics at THP and community based well woman clinics from Medical Officer of Health (MOH) regions in Peradeniya from $1^{\text {st }}$ January 2017 to $31^{\text {st }}$ December 2019. The assessment of smears was performed in two settings. The pap smears received from community based well women clinics were initially screened by two cytoscreeners, and only the suspicious cases were examined by a pathologist. All smears received from gynecological clinics were evaluated by both a postgraduate doctor in histopathology and a pathologist. Five pathologists in the Department of Pathology were involved in reporting the smears in both settings. The method utilized was conventional smears stained with Papanicolaou stain. Cytology reporting was carried out according to the Bethesda criteria 2014 version (4). HPV DNA testing had not been performed on any of the cases.

The main diagnostic categories were negative for intraepithelial lesion or malignancy (NILM), low-grade squamous intraepithelial lesion (LSIL), high-grade squamous intraepithelial lesion (HSIL), atypical squamous cells of undetermined significance (ASCUS), atypical squamous cells - cannot exclude HSIL (ASC-H), glandular cell abnormalities and glandular /squamous cell carcinoma (5). The data was retrieved from archived request forms and the diagnostic rates for each category were calculated.

\section{Results}

There were 1148 satisfactory pap smears reviewed from clinics at THP. Of these, 984 (85.71\%) were NILM, 38 (3.31\%)were LSIL, 3 (0.26\%) were HSIL and 15 (1.31\%) had features of glandular atypia. ASCUS was diagnosed in 105 (9.15\%) and ASC-H in $3(0.26 \%)$ cases. None were diagnosed with a malignancy (Table 1 ).
Table 1: Prevalence of Bethesda diagnostic categories in pap smears reported at clinics in Teaching Hospital Peradeniya from 2017- 2019

\begin{tabular}{|l|c|c|}
\hline $\begin{array}{l}\text { Bethesda } \\
\text { category }\end{array}$ & $\begin{array}{l}\text { Number of } \\
\text { cases } \\
\text { reported }\end{array}$ & $\begin{array}{l}\text { Percentage } \\
\text { of cases }\end{array}$ \\
\hline NILM & 984 & $85.71 \%$ \\
\hline ASCUS & 105 & $9.15 \%$ \\
\hline ASC-H & 3 & $0.26 \%$ \\
\hline LSIL & 38 & $3.31 \%$ \\
\hline HSIL & 3 & $0.26 \%$ \\
\hline $\begin{array}{l}\text { Glandular } \\
\text { atypia }\end{array}$ & 15 & $1.31 \%$ \\
\hline $\begin{array}{l}\text { Squamous } \\
\text { carcinoma }\end{array}$ & 0 & \\
\hline
\end{tabular}

Atypical squamous cells (including both ASC-US and ASC-H) to squamous intraepithelial lesion (including both LSIL and HSIL) ratio was calculated, and the ASC/SIL ratio was 2.6 (5).

There were 9337 satisfactory pap smears from $\mathrm{MOH}$ clinics, of which, 9204 (98.58\%) were NILM, 49 (0.52\%) were LSIL, $3(0.03 \%)$ were HSIL and 5 (0.05\%) had glandular atypia. ASCUS was diagnosed in $71(0.74 \%)$ while $4(0.04 \%)$ showed ASC-H. One case of SCC was reported (Table 2). ASC/SIL ratio was 1.44.

Table 2: Prevalence of Bethesda diagnostic categories in pap smears reported at $\mathrm{MOH}$ clinics in Peradeniya from 2017- 2019

\begin{tabular}{|l|c|c|}
\hline $\begin{array}{l}\text { Bethesda } \\
\text { category }\end{array}$ & $\begin{array}{c}\text { Number of } \\
\text { cases } \\
\text { reported }\end{array}$ & $\begin{array}{c}\text { Percentage } \\
\text { of cases }\end{array}$ \\
\hline NILM & 9204 & $98.58 \%$ \\
\hline ASCUS & 71 & $0.76 \%$ \\
\hline ASC-H & 4 & $0.04 \%$ \\
\hline LSIL & 49 & $0.52 \%$ \\
\hline HSIL & 3 & $0.03 \%$ \\
\hline $\begin{array}{l}\text { Glandular } \\
\text { atypia }\end{array}$ & 5 & $0.05 \%$ \\
\hline $\begin{array}{l}\text { Squamous } \\
\text { carcinoma }\end{array}$ & 1 & $0.0001 \%$ \\
\hline
\end{tabular}




\section{Discussion}

HPV Information Centre statistics indicated that the cumulative risk of cervical cancer in Sri Lankan women in 2019 was $0.8 \%$. This is well below the rates in South Asia and worldwide, where it is about $1.4 \%{ }^{6}$. Therefore, the Sri Lankan community can be considered a low-risk population.

Monitoring the relative frequency of ASC and SIL using ASC/SIL ratio is carried out in the quality assurance of pap smear testing when high-risk HPV testing is not available (5). According to the benchmark data obtained in 2014 (College of American Pathologists), when Bethesda classification is used, a median rate of LSIL diagnosis of $2.5 \%$ and $\mathrm{HSIL}$ diagnosis of $0.5 \%$ with the maintenance of an ASC/SIL ratio of 1.5 is recommended at community level (5).

In our unit, both LSIL and HSIL diagnosis rates in both $\mathrm{MOH}$ and hospital settings are within the accepted rates. The ASC/SIL ratio in the $\mathrm{MOH}$ setting is 1.44 , which is within the accepted limits. However, in the hospital clinic setting, ASC/SIL ratio is 2.6, almost approaching the ratio of highrisk populations due to higher rates of ASCUS diagnoses.

Negative smears in the community samples are not rescreened by the pathologist. Therefore, there is a possibility of having false negative smears, which may be one of the reasons for low rates of positive smears in community samples. Applying the criteria to rescreen at least $10 \%$ of negative smears diagnosed by the cytoscreener by a pathologist will be useful in overcoming this pitfall.

There are many possible reasons for high ASCUS diagnostic rates in the hospital clinic setting in comparison to the community setting. The hospital samples are not comparable to samples from the community setting as most of these patients have an underlying gynecological pathology or other risk factors which result in clinic visits. As several pathologists are involved in the reporting of hospital smears, interobserver variability could be another cause.

The possibility of ASCUS over diagnosis should also be considered. In the Bethesda classification, the ASC diagnosis criterion is given as nuclear size of 2 - 3 times the intermediate cell or twice the size of a metaplastic squamous cell with dense orangeophilic cytoplasm or with HPV cytopathic effects. Background inflammation and related reactive cytological changes could, not infrequently, give rise to such nuclear enlargement. Deviations from these diagnostic criteria can occur during pap smear reporting. Therefore, a follow up audit, after conveying the audit findings and reintroducing the diagnostic criteria for ASCUS to all post graduate doctors and pathologists involved, will indicate the true cause for this high ASC/SIL ratio.

\section{Conclusion}

Diagnostic rates of LSIL and HSIL are within accepted limits both in the hospital samples and community-based samples. However, the ASC/SIL ratio in hospital samples is closer to that of a high-risk population. In community samples, the ratio is within the accepted range for a low-risk population. A follow-up audit after interventional measures is recommended to determine the true cause of this.

\section{References}

1. Sankaranarayanan R.Ferlay J. Preedy VR, Watson RR .Worldwide Burden of Gynecological Cancer.Handbook of Disease Burdens and Quality of Life Measures. 
Springer New York: 2010; https://doi.org/10.1007/978-0-387-78665$\underline{046}$

2. The global cancer observatory. January 2021. International Agency for Research on Cancer: World Health Organization: page1 https://gco.iarc.fr/today/data/factsheets/ populations/144-sri-lanka-fact-sheet

3. Ramu S. Bindu BJ. Murthy N. Pap smear as early diagnostic tool for cervical cancer- $A$ life savior. Pathology Update: Tropical Journal of Pathology \& Microbiology: 2018;4:22- 26.

https://doi.org/10.17511/JOPM.2018.101.0 4

4. Harding C, Seal A, Pilotto L, Mackey K, Duncan $G$, Huynh $R$ et al. Accuracy of
Screening Tools for Pap Smears in General Practice. Journal of Innovation in Health Informatics. 2016;23(3):835.

https://doi.org/10.14236/jhi.v23i3.835

5. Nayar R, Wilbur DC, eds. The Bethesda System for Reporting Cervical Cytology: Definitions, Criteria, and Explanatory Notes. 3rd ed. Cham, Switzerland: Springer; 2015.

6. Bruni $L$, Albero $G$, Serrano $B$, Mena $M$, Gómez D, Muñoz J, Bosch FX, de Sanjosé S. Human Papillomavirus and Related Diseases in Sri Lanka. Summary Report:ICO/IARC Information Centre on HPV and Cancer - HPV Information Centre; June 2019.www.hpvcentre.net 